\title{
Predicting the Effects of Manual Crayfish Removal on California Newt Persistence in Santa Monica Mountain Streams
}

\author{
William R. Milligan ${ }^{\mathrm{b}}$, Marjorie T. Jones ${ }^{\mathrm{a}}$, Lee B. Kats ${ }^{\mathrm{a}}$, Timothy A. Lucas ${ }^{\mathrm{a}, * *}$, Courtney L. \\ Davis, ${ }^{\mathrm{a}, * *}$ \\ ${ }^{a}$ Natural Science Division, Pepperdine University, Malibu, CA 90263, USA \\ ${ }^{b}$ Emory University, Atlanta, GA 30322, USA
}

\begin{abstract}
We construct a hybrid, stage-structured mathematical model to study whether trapping of the invasive predatory crayfish Procambarus clarkii can prevent local extinctions of the California newt (Taricha torosa), a species of special concern native to Santa Monica Mountain streams. Specifically, we numerically and analytically determine under what conditions trapping can drive the crayfish population size to zero. We observe the persistence or the time to extinction for newt populations under corresponding trapping scenarios. No simulations allow for long-term coexistence of newts and crayfish, although multiple scenarios delay newt extinction by several years in the presence of crayfish. We predict that crayfish extinction and newt persistence become more likely as the quantity of trapping resources, frequency of trapping implementation, and susceptibility of the crayfish population to trapping increases. We quantify the effectiveness of different crayfish trapping regimes at delaying the time until the newt population goes extinct. Predictions made with our model inform restorative efforts and crayfish management.
\end{abstract}

Keywords: discrete mathematical model, invasive species, amphibian decline, crayfish management, Taricha torosa, Procambarus clarkii

\footnotetext{
* Corresponding author

** Joint senior authors

Email addresses: william.milligan@emory.edu (William R. Milligan), marjorie.jones@pepperdine.edu (Marjorie T. Jones), lee.kats@pepperdine.edu (Lee B. Kats), timothy.lucas@pepperdine.edu (Timothy A. Lucas), courtney.davis2@pepperdine.edu (Courtney L. Davis,)
} 
- We construct a hybrid mathematical model of newt and crayfish population dynamics.

- No simulations predict long-term coexistence of local newt and crayfish populations.

- We propose crayfish trapping regimes that best prevent or prolong newt extinctions.

- Even intermittent or short-term crayfish trapping can delay newt extinctions.

\section{Introduction}

From 1967 to 1997, global amphibian populations declined 2\% annually, while North American populations experienced sharper downward trends (Houlahan et al., 2000). A third of known amphibian species are unequivocally globally threatened, and over $40 \%$ of amphibian species are experiencing population declines (Stuart et al., 2004). The current extinction rate of amphibians for the past 500 years is an estimated 200 times their background extinction rate based upon amphibian fossil records (McCallum, 2007). No one cause accounts for all declines seen worldwide, but invasive species and habitat loss are established as major contributors (Kats and Ferrer, 2003). Populations of the California newt (Taricha torosa), an amphibian species of special concern, have declined in multiple Santa Monica Mountain (SMM) streams to which the newts are native. Considering that global anthropogenic warming is increasing the probability of droughts like the exceptionally dry and warm period from 2012 to 2015 (Diffenbaugh et al., 2015), newt population declines may be exacerbated by increasingly extreme seasonality in precipitation (Sodhi et al., 2008). Newts are sensitive to drought conditions in their native regions despite living in terrestrial burrows after metamorphosis because adult newts return to SMM streams each year to lay eggs, which hatch to become aquatic larvae (Jones et al., 2017).

Predation by the invasive red swamp crayfish, Procambarus clarkii, is also thought to be a major contributor to the decline of California newt populations (Gamradt et al., 1997). After escaping from aquaculture ponds or being released as live fish bait, $P$. clarkii became an invasive species present in freshwater streams worldwide (Hobbs et al., 1989; Gherardi and Acquistapace, 2007; Gherardi and Holdich, 1999). As an invasive species, the crayfish prey upon and out-compete native species, including native amphibians, invertebrates, and plants (Gherardi and Acquistapace, 2007; Geiger et al., 2005; Gamradt and Kats, 1996; Kats et al., 2013). Red swamp crayfish introduction to SMM streams in the 1960s and 70s has led to drastic decreases in T. torosa populations (Riley et al., 2005). The crayfish attack newt adults and prey upon newt egg masses and larvae to devastating 
degrees (Gamradt et al., 1997; Gamradt and Kats, 1996). These crayfish are pre-adapted to prey upon newts because they are naturally resistant to the potent neurotoxin tetrodotoxin (TTX) within newt eggs and terrestrial newt lifestages (Gamradt and Kats, 1996; Barbaresi and Gherardi, 2000).

Four streams in the SMM are distinct and naturally lend themselves to scientific study of newt and crayfish populations. Cold Creek has remained relatively pristine with no crayfish populations and with a declining adult newt population due to drought (Kats et al., 2013). Malibu Creek contains robust populations of crayfish and other invasive species, and as of 2016 newts have not been seen for over 20 years due to local extinction from crayfish predation (Gamradt and Kats, 1996). Trancas Creek and Las Virgenes Creek offer unique locations where flooding events have periodically flushed crayfish from the stream, which temporarily reduces the crayfish population (Gamradt and Kats, 1996; Kats et al., 2013). The red swamp crayfish are native to the slowmoving water of the southeastern United States and are washed away by high velocity flooding in SMM streams with steeper gradients. In field surveys taken the year before a flooding event in 1995, Gamradt and Kats (1996) found that crayfish were present in Trancas Creek at appreciable densities (0.58 crayfish per square meter) with zero observed newt adults, egg masses, or larvae. After the flooding event, they found no crayfish and 67 newt egg masses, 14 adult newts, and newt larvae at a mean density of 8.2 larvae per square meter (Gamradt and Kats, 1996). Thus, these periodic flooding events allow newts to reproduce in a temporarily crayfish-free stream and persist despite crayfish invasion. However, prolonged drought has made flooding events increasingly rare. Multiple studies have projected an elevated risk of severe drought in the coming years (Cook et al., 2015; Diffenbaugh et al., 2015; Underwood, 2015), and thus natural mechanisms for controlling crayfish populations such as flooding events and high velocity stream flow may be insufficient for newt persistence without the help of restorative measures.

We examine if reducing a crayfish population via trapping with nets and baited cage traps can bolster a newt population. In a review of crayfish management techniques, Gherardi and Holdich (1999) found that manual removal (i.e., removal by hand and using traps) is highly effective at reducing the crayfish population, especially adults, and has low ecological impacts compared to other management strategies such as physical drainage and biocides. In Trancas Creek, Kats et al. (2013) have shown that manually reducing crayfish populations using baited traps allowed newts to successfully reproduce during that season. Also, Aquiloni et al. (2010) reduced a crayfish population via manual crayfish trapping from a pond and an artificial canal in Italy. However, in both cases 
the crayfish population rebounded once trapping ceased. Given that there have been few reported successful eradications of invertebrates in North America (Cox, 1999) and none in Europe (Genovesi, 2005), in this system, in the absence of flooding events, sustained trapping appears to be one of the best mechanisms for crayfish management.

Most mathematical models of $P$. clarkii predict population dynamics from an aquaculture context, such as Anastácio et al. (1999), although Martelloni et al. (2012) models P. clarkii crayfish populations invading a hypothetical lake. However, none have modeled newt and crayfish interactions in the wild. We have developed in parallel a separate newt population stage-structured model to examine the impact of drought on newt persistence (Jones et al., 2017) in the absence of crayfish. We now explore the impact of restorative measures, such as crayfish trapping, on newt persistence or time to extinction in streams with crayfish present. By merging a set of delayed, stage-structured difference equations to model newt population dynamics with a differential equation to describe crayfish population dynamics, we examine how often and to what magnitude intermittent or persistent manual crayfish removal must occur to prevent local newt extinction.

\section{Methods}

\subsection{Crayfish Model}

Crayfish can reach maturity in as little as three months - much more quickly than the newtsand produce offspring multiple times per year. A single female crayfish can produce 450-500 eggs per season, which even with high mortality supports a high population growth rate (GutirrezYurrita and Montes, 1999). Furthermore, P. clarkii is an opportunistically reproducing species, as females will carry eggs to release when conditions are favorable (Gherardi and Holdich, 1999). In addition, crayfish have a high turnover rate due to their short lifespan of 12-18 months (Scalici and Gherardi, 2007). Crayfish exhibit density-dependent aggression in which a 3-fold increase in crayfish density results in a 27-fold increase in aggression; however, crayfish dispersal rates do not increase as crayfish density increases (Kats et al., 2006). Since crayfish populations, $C$, have a rapid growth rate and lay eggs multiple times per year with overlapping generations (Huner and Lindqvist, 1995), we model crayfish continuously with a differential equation. Growth of individual crayfish is stunted as the density of crayfish increases (Ramalho et al., 2008; McClain, 1995), and crayfish fecundity decreases with diminished size (Eversole and Mazlum, 2002). Therefore, we assume logistic growth on a yearly time scale $t$ with a population growth rate $r$ and carrying capacity $K_{C}$. 
We assume that any benefit to crayfish from newt predation is negligible, as it is unclear if crayfish prey upon newts for sustenance or attack them due to territorial instinct. Furthermore, crayfish are polytrophic omnivores, which means that they prey upon a variety of organisms (Huner and Lindqvist, 1995) and are not dependent upon newts for energy. Whether crayfish are harmed by newt predation is equivocal as the TTX that metamorphosed newts and newt eggs possess is lethal to crayfish if injected under the crayfish carapace, yet crayfish appear to tolerate TTX ingestion (Gamradt and Kats, 1996; Barbaresi and Gherardi, 2000). Thus, we assume interactions with newts are neither beneficial nor detrimental to crayfish in our model.

The number of crayfish removed via trapping depends upon the current crayfish population size and the quantity of crayfish caught with the implemented trapping resources. Not all crayfish are susceptible to being removed by trapping; for example, young crayfish are too small to be trapped and crayfish can burrow into stream banks for weeks at a time (Correia and Óscar Ferreira, 1995; Gherardi and Holdich, 1999; Huner, 2009). Thus, the quantity of crayfish removed each month is modeled by subtracting the minimum between $T$, the total capacity of traps in terms of crayfish, or $\xi C$, the maximum number of crayfish available to be removed per month. Hence, the function we use to model crayfish population dynamics is

$$
\frac{d C}{d t}=r C\left(1-\frac{C}{K_{C}}\right)-\mathbb{X}_{\kappa} \min (T, \xi C)
$$

where the value of $\mathbb{X}_{\kappa}$ is 12 during the set of months, $\kappa$, that trapping occurs to convert monthly trapping to a yearly time scale. The value of $\mathbb{X}_{\kappa}$ is zero when no trapping occurs. We define $C_{k, t}$ to be the number of crayfish in month $k$ and year $t$ in order to combine the continuous crayfish equation and the following discrete newt equations.

\subsection{Newt Model}

Fig. 1 shows the four life stages of the California newt. Adult and juvenile newts are terrestrial and spend the majority of the year in burrows. Each year around April, adult newts return to breed and lay eggs in SMM streams, where they are native. In May, newt eggs hatch and become aquatic larvae (Ritter, 1897; Gamradt and Kats, 1996). Unlike the other newt life stages, TTX levels become almost negligible in newt larvae, and thus they face predation from native and invasive predators (Twitty, 1937). In September, larvae metamorphose into juvenile newts, which are terrestrial and do not necessarily return to aquatic habitats during the juvenile stage. Six years 
after metamorphosis, juvenile $T$. torosa become reproductively mature adults and return to the same streams once per year to lay eggs (Gamradt and Kats, 1996). Adult newts that breed at a particular stream are considered a distinct population because newts are site tenacious, which means they return to the same stream each year with negligible migration between streams (Twitty, 1942; Gamradt and Kats, 1997).

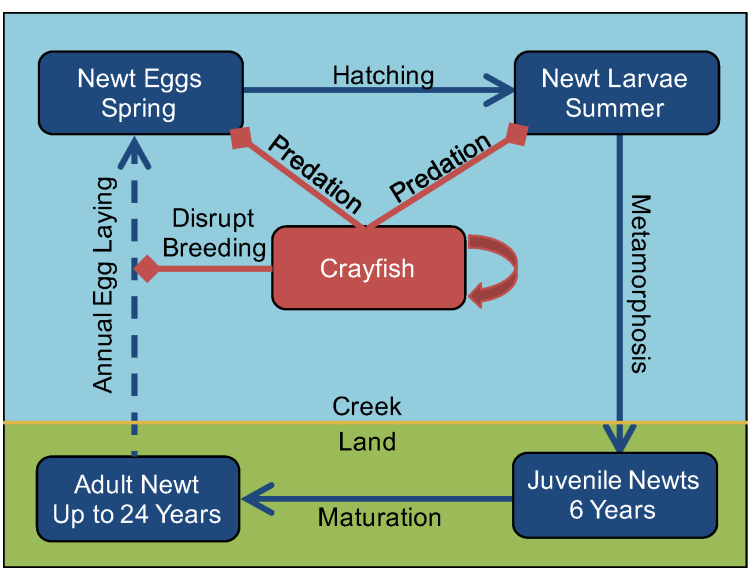

Fig. 1. Life cycle of a California newt, Taricha torosa. The dotted blue arrow represents the annual migration of adults to SMM streams, while solid blue lines indicate transitions between life stages. Newt eggs and larvae are aquatic, but adult and juvenile newts live on land in terrestrial burrows, as indicated by the blue and green backgrounds. The red arrow indicates crayfish population growth while red line segments denote crayfish-newt interactions.

Crayfish presence in streams inhibits newt egg-laying (Gamradt et al., 1997). We model newt egg production using a Michaelis-Menten enzyme kinetics metaphor where stream habitat space acts as a catalyst and crayfish competitively inhibit newt egg-laying. This builds upon the crayfishfree discrete model of newt populations in Jones et al. (2017). During the breeding season, newts maintain a roughly 1:1 sex ratio given a sufficiently large population (Marshall et al., 1990), so we assume the fertile female egg population is $A_{L}=A_{t} / 2$ newts, where $A_{t}$ is the number of adult newts at time $t$. A female newt can reproduce once per year and lays 2-3 egg masses with 15-30 embryos each (Brame, 1968; Kats et al., 2013). We average these and assume a female newt can lay $\alpha=60$ eggs per year. After laying eggs, a newt becomes sterile, $A_{S}$, until the next year's mating season. The metaphorical reaction between the newts, crayfish, and stream habitat space, $H$, used 
to derive our egg production term is

$$
\begin{aligned}
A_{L}+H & \rightleftharpoons A H \rightarrow \alpha \operatorname{Eggs}+H+A_{S} \\
C+H & \rightleftharpoons C H .
\end{aligned}
$$

Not all female newts successfully lay in each mating season. Newts compete with each other for stream habitat space, which is represented by $\beta_{N}$, the number of female newts at which half of the females can lay eggs under the Michaelis-Menten metaphor. Suitable breeding habitat for newts is further limited by the presence of aggressive crayfish in streams. The effectiveness of crayfish inhibition on newt egg-laying is represented by $\beta_{C}$, the number of crayfish required to reduce newt egg-laying by half. Thus, following a derivation analogous to that in Jones et al. (2017), the equation for the number of eggs produced in April (month 4) of year $t$ that corresponds to (2) is

$$
E_{4, t}=\frac{\alpha \frac{A_{t}}{2}}{\left(1+\frac{A_{t}}{2 \beta_{N}}+\frac{C_{4, t}}{\beta_{C}}\right)} .
$$

Newt eggs and larvae together compromise the aquatic newt population, and both face predation from crayfish. Aquatic newts preyed upon by crayfish are removed at a rate proportional to the number of predator-prey interactions. However, crayfish are territorial and attack each other at a rate $\omega_{C}$, which limits interactions with newts. Because these crayfish-crayfish interactions are not instantaneous and last $\tau$ hours, predation on aquatic newt life stages from crayfish is modeled using a Beddington-DeAngelis functional response (Beddington, 1975; DeAngelis et al., 1975). Newt deaths due to predation in month $k$ of year $t$ are given by a function of $N_{k, t}$, the aquatic newt population, and $C_{k, t}$, the crayfish population. The predation function is defined as

$$
P\left(N_{k, t}, C_{k, t}\right)=\frac{\omega_{N} N_{k, t} C_{k, t}}{1+\omega_{C} \tau\left(C_{k, t}-1\right)},
$$

where $\omega_{N}$ is the number of aquatic newt-crayfish interactions per crayfish (Beddington, 1975). Since Kats et al. (2006) found that crayfish predation on newt eggs is $85 \%$ as effective as crayfish predation on newt larvae, $P$ is scaled by 0.85 for egg predation. Newt eggs that survive crayfish predation through May hatch in early June and transition to larvae with probability $\lambda_{E}$. Although the natural mortality rate of newt eggs is negligible, newt larvae compete for resources and are not protected by TTX (Kats et al., 2006), so larvae survive at a rate $\sigma_{L}$ per month. In month $k$ and year $t$, the populations of newt eggs, $E_{k, t}$, and newt larvae, $L_{k, t}$ persist, transition, and are preyed 
upon as follows:

$$
\begin{aligned}
& E_{5, t}=E_{4, t}-0.85 P\left(E_{4, t}, C_{4, t}\right) \\
& L_{6, t}=\lambda_{E}\left(E_{5, t}-0.85 P\left(E_{5, t}, C_{5, t}\right)\right) \\
& L_{k, t}=\sigma_{L}\left(L_{k-1, t}-P\left(L_{k-1, t}, C_{k-1, t}\right)\right) \text { for } 7 \leq k \leq 9
\end{aligned}
$$

where $k$ is restricted since larvae only exist from June to September.

We update the juvenile and adult newt equations in the spring, when the field surveys that count egg masses are typically completed. Larvae from September of the previous year are added to the juvenile population with an implied unit conversion of one juvenile per larvae. We assume juvenile newts, $J_{t}$, survive year to year at a rate $\sigma_{N}$ and that juveniles that have survived for six years become adults. Therefore, the number of juveniles that transition to adulthood each year is defined in terms of surviving larvae that metamorphosed six years previously. That is,

$$
j_{t-6}=\sigma_{N}^{6} L_{9, t-6} .
$$

Thus, the juvenile newt population in year $t+1$ is given by $J_{t+1}$ and updated annually to include surviving juveniles, transitioning juveniles, and new juveniles via

$$
J_{t+1}=\sigma_{N} J_{t}-j_{t-6}+L_{9, t} .
$$

Due to the lack of field data tracking juvenile newts, we make the simplifying assumption that juvenile and adult newts face similar environmental challenges that influence survivorship. Thus, we assume juveniles and adults survive year to year at the same rate, $\sigma_{N}$. We also assume terrestrial newts have a maximum lifespan of 30 years, so the number of adult newts that survive to the maximum lifespan are represented by the number of surviving newt larvae that transitioned to juveniles 30 years ago via

$$
a_{t-30}=\sigma_{N}^{30} L_{9, t-30} .
$$

Thus, the adult newt population in year $t$ is given by $A_{t}$ and updated annually to include surviving adults, transitioning juveniles, and adults that reach the age limit and die via

$$
A_{t+1}=\sigma_{N} A_{t}+j_{t-6}-a_{t-30} .
$$

The full model of newt-crayfish population dynamics is (1) and (3)-(11). 


\subsection{Parameterization}

The parameter values used in this model are given in Table 1 and are based on empirical values found in the literature as well as field observations of SMM streams. We assume that the simulated newt and crayfish populations live in or around a 400 meter length of stream with a crayfish carrying capacity, $\kappa_{C}$, of 10,000 crayfish. Based upon personal observations, the average length of crayfish-crayfish interactions, $\tau$, is set to $1 / 60$ hours ( 1 minute). We calculate the crayfish population growth rate, $r$, to be 1.5 per year by averaging data collected by Rhodes and Avault (1986), who determined the crayfish population size in 14 previously empty ponds 310 days after stocking with a known quantity of crayfish.

We vary the monthly trapping capacity, $T$, between 200 and 5,000 crayfish per month, that is, $2 \%$ and $50 \%$ of the crayfish carrying capacity. The maximum rate of crayfish removal per month, $\xi$, which corresponds to the proportion of the crayfish population that is available to be trapped, is fit to field data that describe the number of crayfish removed per week in 2003 in Trancas Creek from May to July. We calculate $\xi=0.693$ per month, which corresponds to a maximum reduction of the crayfish population by $50 \%$ each month.

We assume that the number of newt eggs that survive to metamorphosis yields approximately 0.025 juveniles per egg, which is an average of egg-to-juvenile survival estimates given by Sever et al. (1986). We assume all newt larvae that survive to metamorphosis also survive metamorphosis itself and thus undergo a unit conversion of one juvenile per larvae. Given that controlled field experiments indicate that newt eggs survive through hatching at a rate $\lambda_{E}=0.95$ larvae per egg (Kats et al., 2006), the survival probability of the newt larvae, $\sigma_{L}$, is set at 0.2974 so that the product of $\lambda_{E} \sigma_{L}^{3}$ is 0.025 juveniles per egg.

From Jones et al. (2017), we estimate $\beta_{N}$, the number of adult female newts where half of the females have enough resources to lay eggs. We use a $\beta_{N}$ of 100 female newts, which corresponds to 30 $\mathrm{cm}$ of precipitation, the average annual precipitation recorded at Los Angeles International Airport from 1945 to 2015 (WRCC, 2015). However, we note that since the average rainfall decreased to $26 \mathrm{~cm}$ in 2000 to 2015, using the longer-term average may overestimate newt populations.

No study documents the value of $\beta_{C}$, the number of crayfish at which only half of female newts can lay eggs. Kats et al. (2013) found that newt egg production is more sensitive to aggression from crayfish populations than intraspecies competition. Since we lack sufficient data to precisely calculate this parameter, we make an assumption that crayfish aggression has a ten-fold impact 
on newt egg-laying compared to competition among newts for stream space; this corresponds to $\beta_{C}=2 \beta_{N}$ when there are 10,000 crayfish and 1,000 adult newts. Using a $\beta_{N}$ of 100 adult newts, $\beta_{C}=200$ crayfish.

Similarly, the number of crayfish-larvae interactions per crayfish, $\omega_{N}$, is unknown, yet there is a positivity constraint on $\omega_{N}$. Since (7) cannot be negative,

$$
1-\frac{\omega_{N} C_{k-1, t}}{1+\omega_{C} \tau\left(C_{k-1, t}-1\right)} \geq 0 .
$$

Since death due to predation increases with an increased crayfish population, we maximize crayfish predation by assuming that $C_{k-1, t}$ is at carrying capacity, $K_{C}$. Enforcing positivity and solving for the maximum $\omega_{N}$ gives

$$
\omega_{N} \leq \frac{1+\omega_{C} \tau\left(K_{C}-1\right)}{K_{C}}=0.1334 \text { interactions per crayfish. }
$$

This condition is also sufficient to ensure positivity for (5) and (6). Therefore, we vary $\omega_{N}$ between 0 and 0.1334 interactions per crayfish and analyze the long-term behavior of the newt population. With the help of periodic flooding, newts have avoided extinction in the presence of crayfish at Trancas Creek; however, the local newt population went extinct in Malibu Creek within 30 years of crayfish invasion (Gamradt and Kats, 1996; Riley et al., 2005). We chose $\omega_{N}$ to be 0.040 interactions per crayfish, which is the smallest value of $\omega_{N}$ at which the newt population goes locally extinct at 30 years with fewer than 5 newts. Because adult newts do not experience direct crayfish predation, the minimum possible time to extinction following invasion by crayfish is 30 years, the maximum newt lifespan. All other parameters are taken from sources in the literature as described in Table 1.

\subsection{Simulations}

We numerically solve the crayfish population equation (1) and output $C_{k, t}$, the number of crayfish at the beginning of month $k$ of year $t$, on a monthly basis to inform the crayfish-newt interactions in the newt egg and larval stages. For the newt population, the juvenile and adult newt equations are updated first so that the number of eggs laid in year $t$ includes eggs laid by juveniles that matured to adults in year $t$. We then update the egg and larval populations in monthly succession. Due to the 30-year delay term in (11), the newt populations are initialized with equilibrium values for the 30 years before $t=0$, the first year simulated by the model. For 
Table 1. Parameter values for the model given by (1)-(11)

\begin{tabular}{|c|c|c|c|}
\hline Parameter & Value & Description & Citation \\
\hline$r$ & 1.5 per year & Growth rate of crayfish & $\begin{array}{l}\text { Rhodes and Avault } \\
(1986)\end{array}$ \\
\hline$K_{C}$ & 10,000 crayfish & Crayfish carrying capacity for stream & Stream-specific \\
\hline$\alpha$ & 60 eggs per female & Number of eggs per female per lay & Kats et al. (2013) \\
\hline$\beta_{N}$ & 100 female newts & $\begin{array}{l}\text { Number of adult female newts at } \\
\text { which half of female newts can lay } \\
\text { eggs }\end{array}$ & Jones et al. (2017) \\
\hline$\lambda_{E}$ & 0.95 larvae per egg & $\begin{array}{l}\text { Survival probability of eggs hatching } \\
\text { into larvae }\end{array}$ & $\begin{array}{l}\text { Gamradt and Kats } \\
(1996)\end{array}$ \\
\hline$\sigma_{L}$ & 0.2974 & Survival probability of larvae & $\begin{array}{l}\text { Calculated from } \\
\text { Sever et al. (1986) }\end{array}$ \\
\hline$\omega_{C}$ & 8 per crayfish per hour & $\begin{array}{l}\text { Rate of crayfish-crayfish interactions } \\
\text { per hour }\end{array}$ & Issa et al. (1999) \\
\hline$\tau$ & $1 / 60$ hours ( 1 minute $)$ & $\begin{array}{l}\text { Average length of crayfish-crayfish } \\
\text { interactions }\end{array}$ & $\begin{array}{l}\text { Personal } \\
\text { oberservation }\end{array}$ \\
\hline$\sigma_{N}$ & 0.91 & $\begin{array}{l}\text { Annual survival probability of } \\
\text { juvenile and adult newts }\end{array}$ & Twitty (1966) \\
\hline$\xi$ & 0.693 per month & $\begin{array}{l}\text { Maximum rate of crayfish removal } \\
\text { per month }\end{array}$ & $\begin{array}{l}\text { Calculated from } \\
\text { Trancas Creek } \\
\text { trapping data }\end{array}$ \\
\hline$\beta_{C}$ & 200 crayfish & $\begin{array}{l}\text { Crayfish population at which half of } \\
\text { female newts can lay eggs }\end{array}$ & Varied \\
\hline$\omega_{N}$ & 0.04 per crayfish & $\begin{array}{l}\text { Probability of crayfish-larvae } \\
\text { interactions per crayfish }\end{array}$ & Varied \\
\hline$T$ & $200-5,000$ crayfish per month & $\begin{array}{l}\text { Maximum number of crayfish } \\
\text { removed per month }\end{array}$ & Varied \\
\hline
\end{tabular}




$$
A=2 \beta_{N}\left(\frac{\alpha \lambda_{E} \sigma_{L}^{3}}{2\left(1-\sigma_{N}\right)} \prod_{k=7}^{9}\left(1-\frac{\omega_{N} C_{k-1}}{1+\omega_{C} \tau\left(C_{k-1}-1\right)}\right) \prod_{k=5}^{6}\left(1-\frac{0.85 \omega_{N} C_{k-1}}{1+\omega_{C} \tau\left(C_{k-1}-1\right)}\right)\left(\sigma_{N}^{6}-\sigma_{N}^{30}\right)-1-\frac{C_{4}}{\beta_{C}}\right) .
$$

simulations of an established crayfish population, we allow an additional six years of initialization during which the crayfish grow unfettered to $99 \%$ of the carrying capacity, $K_{C}$. The resulting impact of crayfish presence on the adult newt population is delayed these six years because of the pre-existing juvenile population. We introduce different crayfish trapping regimes by varying the trapping capacity each month as well as the frequency of trapping on both a monthly and yearly basis. In this way, we use the parameterized model (1) and (3)-(11) to evaluate the effectiveness of manual crayfish trapping schedules on newt persistence and to determine the long-term equilibrium values of the newt population.

\section{Results}

\subsection{Analytical Persistence}

General equilibrium values of the newt population can be found for two cases: newts present without crayfish and newts present with crayfish but without crayfish trapping. Since population counts will be identical year to year upon reaching equilibrium, we drop the yearly subscripts. Notice that a trivial solution where all newt life stages are zero is immediately apparent. However, we are interested in equilibria where the newt population does not go extinct. Substituting (3) into (5) and moving iteratively from $E_{4}$ to $L_{9}$, we calculate the larval population that metamorphoses in September (month 9). We substitute this into (11) using (8) and (10) to find the equilibrium newt population. The nontrivial (nonzero) equilibrium for the adult newt population is

When there are no crayfish in the stream, then $C=0$, and using the parameter values from Table 1, (14) simplifies to

$$
A=2 \beta_{N}\left(\frac{\alpha \lambda_{E} \sigma_{L}^{3}}{2\left(1-\sigma_{N}\right)}\left(\sigma_{N}^{6}-\sigma_{N}^{30}\right)-1\right)=648 \text { adult newts. }
$$

The corresponding equilibrium juvenile population is

$$
J=\frac{\alpha \frac{A}{2} \lambda_{E} \sigma_{L}^{3}}{1+\frac{A}{2 \beta_{N}}}\left(\frac{1-\sigma_{N}^{6}}{1-\sigma_{N}}\right)=550 \text { juvenile newts. }
$$

The adult newt equilibrium population of 648 adult newts is greater than current estimates of the Cold Creek population of 572 adult newts (Bucciarelli et al., unpublished), which is expected 
since our model does not incorporate newt population declines due to drought. Equation (15) is consistent with the equilibrium solution of the newt population model by Jones et al. (2017), which predicts 651 adult newts in the absence of drought. When crayfish are present but no trapping regime is implemented, we assume $C$ is constant and (14) reduces to

$$
A=2 \beta_{N}\left(\frac{\alpha \lambda_{E} \sigma_{L}^{3}}{2\left(1-\sigma_{N}\right)}\left(1-\frac{\omega_{N} C}{1+\omega_{C} \tau(C-1)}\right)^{3}\left(1-\frac{0.85 \omega_{N} C}{1+\omega_{C} \tau(C-1)}\right)^{2}\left(\sigma_{N}^{6}-\sigma_{N}^{30}\right)-1-\frac{C}{\beta_{C}}\right) .
$$

With an established crayfish population, (17) is negative when evaluated with the parameters from Table 1. A nonnegative newt equilibrium would only exist if the crayfish population is sustained at less than 33 crayfish. Even if $100 \%$ of newts survive annually $\left(\sigma_{N}=1\right)$, a positive newt equilibrium is only possible if the crayfish population does not exceed 538 crayfish. We also find that the number of crayfish that can be present for coexistence is largely insensitive to $\beta_{C}$ when $91 \%$ of newts survive annually. As $\sigma_{N}$ increases to 1 , the number of crayfish that allows for newt coexistence at most doubles. Thus, the local newt population will go extinct (that is, go to the trivial equilibrium) without intervention, which is expected given that local extinctions of newt populations have occurred in multiple SMM creeks inhabited by invasive crayfish (Gamradt and Kats, 1996). Furthermore, (14) demonstrates $\beta_{N}$ affects the value but not the existence of a nontrivial adult newt equilibrium; therefore, the prediction of newt extinction given by (17) occurs regardless of drought severity and is due solely to crayfish invasion.

We now consider equilibrium values for the crayfish population. Due to the discrete nature of the crayfish trapping implementation, (1) cannot be algebraically solved for equilibria. However, we can separately analyze the cases where trapping is proportional to the total crayfish population,

$$
\frac{d C}{d t}=r C\left(1-\frac{C}{K_{C}}\right)-M \xi C,
$$

and where trapping is only limited by the capacity of traps,

$$
\frac{d C}{d t}=r C\left(1-\frac{C}{K_{C}}\right)-M T .
$$

Here, $M$ is the number of months in which trapping occurs each year. Fig. 2 shows how the solutions to (18) and (19) correspond to the crayfish model in each case. A continuous trapping rate of $M \xi C$ or $M T$ matches the behavior of the crayfish model (1) with a trapping rate $12 \min (\xi C, T)$ during a discrete set, $\kappa$, of size $M$ months. By analyzing the equilibrium solutions of (18) and (19), we 


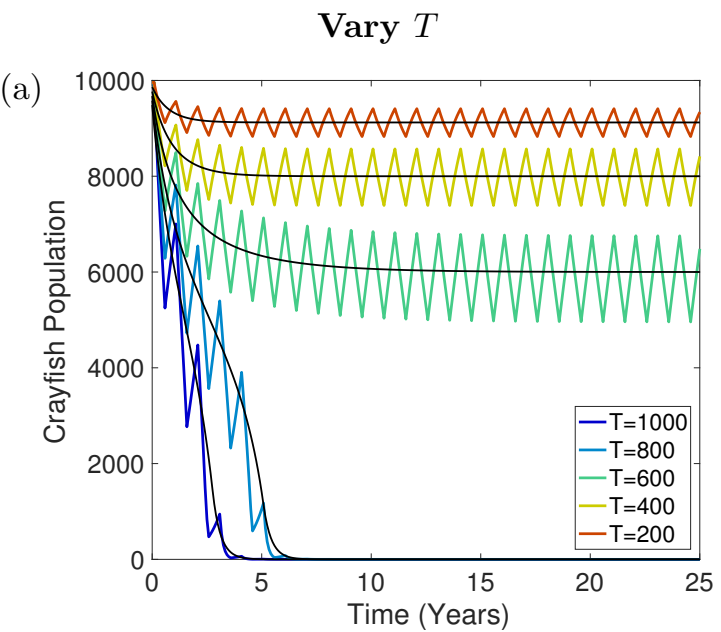
elimination of the crayfish population. determine threshold values for the trapping parameters $M, \xi$, and $T$ that theoretically lead to the

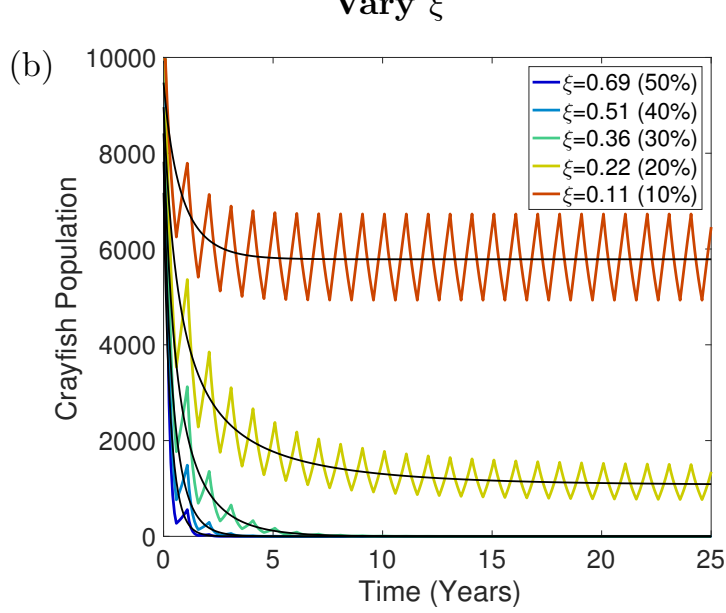

Fig. 2. Numerical and analytical solutions for the crayfish populations when varying $T$ and $\xi$. In (a), $\xi$ is fixed at 0.693 per month, which corresponds to trapping $50 \%$ of the crayfish population per month, while $T$ is varied between 200 and 1,000 crayfish per month. In (b), $T$ is fixed at 1,000 crayfish per month, and $\xi$ is varied between 0.11 and 0.693 per month. The percentages next to the legend entries in (b) correspond to the maximum proportion of the crayfish population that can be removed per month. In both (a) and (b), crayfish are trapped from March to August, although the analytical solutions (black) only use the number of months trapped per year and not the order. Furthermore, the analytical solutions roughly correspond to the center of the oscillations in the numerical solutions caused by periodic trapping. In each case, lower values of $T$ or $\xi$ allow the crayfish population to reach a nonzero equilibrium. In figures and tables following, we do not vary $\xi$, as $\xi$ is likely inherent to a crayfish population.

The nontrivial (nonzero) equilibrium for (18),

$$
C=\frac{K_{C}}{r}(r-M \xi),
$$

is only positive for $M \xi<r$. We note that when $M \xi=r,(18)$ has a transcritical bifurcation below which a positive nontrivial equilibrium no longer exists. Therefore, the model predicts that the crayfish population will approach extinction if $M \xi>r$, i.e., if the effectiveness of the trapping regime 
is greater than the crayfish population growth rate. This condition means that it is theoretically possible to eliminate the crayfish population by increasing $\xi$, the maximum rate that crayfish can inherently be trapped, or increasing $M$, the number of trapping months per year, up to a maximum of 12 months. Since $\xi$ is limited by inherent properties of each crayfish population (such as burrowing rate and juvenile size) as well as by constraints on trap mesh sizes, it is difficult to change. However, the effectiveness of trapping can still be improved by increasing the number of months trapped.

Similarly, the equilibrium solutions for (19),

$$
C=\frac{r K_{C} \pm \sqrt{r K_{C}\left(r K_{C}-4 M T\right)}}{2 r}
$$

only exist if $M T<r K_{C} / 4$. We note that (19) has a saddle-node bifurcation where the equilibrium solutions disappear for $M T>r K_{C} / 4$. In the latter case, solutions to (19) trend to zero. This means that the number of trapping months, $M$, and the trapping capacity, $T$, can theoretically be chosen based upon the size and growth rate of the population in order to guarantee that the crayfish population will eventually be eliminated.

In our crayfish model (1), the trapping term switches between $T$ and $\xi C$ instantaneously, and therefore not all equilibria values given in (20) and (21) can be physically achieved. If the output from (20) is below or if the output from (21) is above $C=T / \xi$ crayfish, that respective equilibrium will be feasible. Thus, we can determine the equilibrium value of (1) using the continuous rate $M$ to approximate the discrete function $\mathbb{X}_{\kappa}$ for a range of pairs of $\xi$ and $T$. We verify this approximation by observing the lowest value of the long-term crayfish population that is predicted by numerical simulations of the model for a range of pairs of $T$ and $\xi$ using every possible set of 3 or 6 month trapping schedules. The numerical results agree with the analytical approximation as seen when comparing the analytical crayfish equilibria in Fig. 3(a) and Fig. 3(c) to the average minimum number of crayfish when trapping for 3 and 6 months in Fig. 3(b) and Fig. 3(d). As more months are trapped, lower values of $\xi$ and $T$ lead to crayfish eradication. However, there are always threshold values of $\xi$ and $T$ below which the crayfish persist. Numerical simulations predict a slightly lower threshold because analytical simulations do not capture the oscillations generated by periodic trapping. In either, if adequate resources are allotted for trapping, a sufficiently susceptible crayfish population can go extinct. 
Analytical

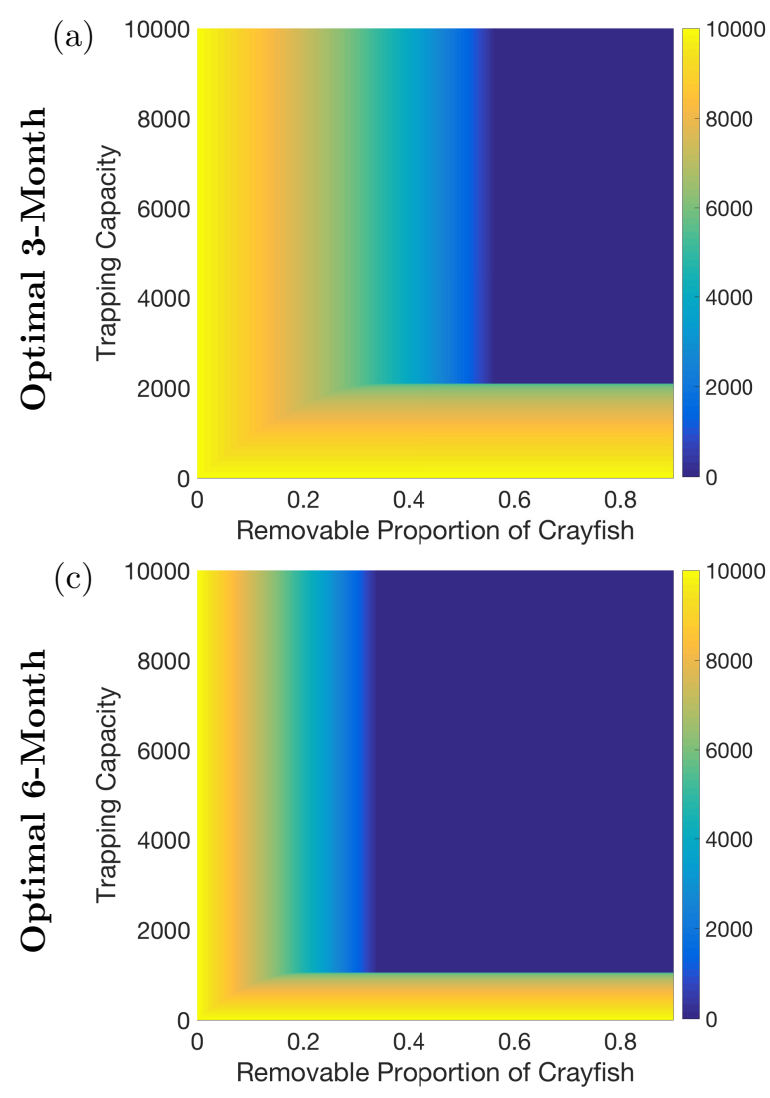

Numerical

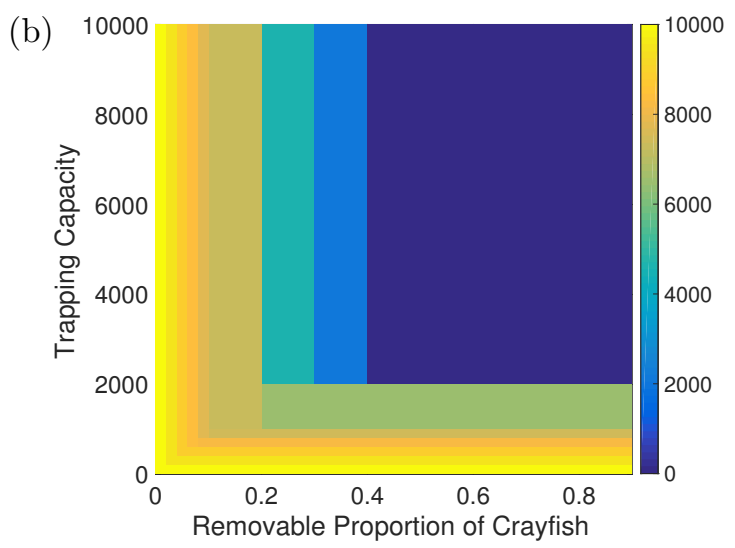

(d)

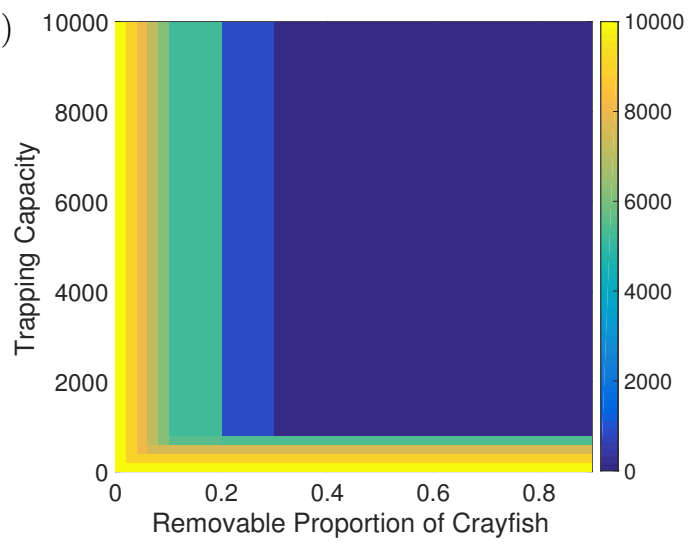

Fig. 3. The effects on a crayfish population of varying $\xi$, which corresponds to the maximum removable proportion of the crayfish population per month, and $T$, the trapping capacity and hence the maximum quantity of removed crayfish per month. Figures (a) and (c) are the relevant longterm crayfish populations calculated from (20) and (21) with (a) 3 months and (c) 6 months of trapping. Figures (b) and (d) show the average minimum number of crayfish populations found using numerical simulations for (b) 3 months and (d) 6 months of trapping. Numerical and analytical solutions largely agree except at the boundaries between crayfish extinction or persistence because analytical simulations do not capture the oscillatory behavior of periodic trapping. 


\subsection{Validation}

We validate our model both with and without crayfish present. We compare the output of our newt-only model, (3)-(11), to field data from Cold Creek, a pristine SMM stream, to ensure our model produces realistic results in the absence of crayfish. Mark-recapture data analysis estimates that the adult newt population at Cold Creek was 1025 adults from 1993-2000, but by 2013 the population declined to an estimated 572 adults (Bucciarelli et al., unpublished). There are no estimates of the juvenile newt population size. However, if we assume that the adult newt population was stable from 1993 to 2000, that is, if the adult newts that died each year were replaced by an equal number of maturing juveniles, we estimate the juvenile newt population to be 470 newts using (16). Thus, our initial conditions for validation are 0 crayfish, 1,000 adults newts, 470 juvenile newts, and 0 eggs or larvae. Given these initial conditions in 2000, the newt-only model predicts a population of 795 adult newts in 2013 . The model predicts a higher number of adult newts than were observed likely because the model uses the long-term average rainfall of $30 \mathrm{~cm}$ from 1945 to 2015 rather than using only the lower-than-average rainfall since 2000. If we incorporate the effects of drought as in Jones et al. (2017) by setting $\beta_{N}=75$ to match the rainfall average of $26 \mathrm{~cm}$ from 2000 to 2015 , our models predicts 686 adult newts in 2013. Furthermore, at the crayfish-free newt equilibrium during drought, our model (15) predicts 485 adult newts and Jones et al. (2017) similarly predicts 497 adult newts.

To validate our trapping mechanism used in (1), we use data from a trapping effort in 450 meters of Trancas Creek where 100 crayfish traps were deployed from May to July in 2003 and the number of crayfish removed each week was recorded. We vary $T, \xi$, and $K_{C}$ (the crayfish carrying capacity) to determine if there exists a set of trapping parameters that matches the quantity of crayfish removed in the field study. The best-fit parameter set is $K_{C}=1,400$ crayfish, $T \geq 800$ crayfish per month, and $\xi=0.693$ per month, which corresponds to $50 \%$ of crayfish being available to be trapped. In this scenario the model predicts that 707, 373, and 204 crayfish would be removed in May, June, and July, respectively, which is similar to the data where 708, 381, and 209 crayfish were removed in these months (unpublished data).

\subsection{Optimal Crayfish Trapping Regimes}

Manual crayfish removal via trapping has traditionally been carried out in SMM streams from May to July. To determine if this or another schedule is optimal for trapping, we use the number of 
new juveniles produced in the last year of trapping as a measure of how well a proposed trapping regime benefits the newt population. We limit our analysis to the first six years, a period when the adult newt population is independent of trapping due to the six-year delay in juvenile newt maturation. The months that trapping can occur is restricted to March through November as crayfish traps may wash away during winter rains. Thus, we simulate newt and crayfish populations given all possible 3-and 6-month trapping schedules to determine which regime maximizes the number of new juveniles produced in the last year of trapping. Table 2 describes the optimal three-month and six-month trapping regimes when trapping occurs for a span of 2 or 5 years and $T$ is varied between 200 and 5,000 crayfish per month. In general, it is best to trap in the months leading up to egg-laying when trapping for shorter time periods at lower $T$ values. However, for greater $T$ values, the optimal 3-month and 6-month trapping regimes become March-May and March-August, respectively. When trapping is allowed to occur during the winter months, the same pattern holds except that for greater $T$ values the optimal 3-month and 6-month regimes are February-April and January-June, respectively. In general, the optimal trapping regimes reduce the crayfish population leading up to egg production and also prevent subsequent predation. This is predictible since trapping cannot protect aquatic newts in later months if crayfish prevent egg-laying in April. For greater values of $T$ and as time progresses, it becomes easier to protect egg-laying without earlier trapping, and thus it becomes optimal to trap in months that also protect the remaining aquatic life stages. For all subsequent numerical simulations, we use March-May as the optimal 3-month and March-August as the optimal 6-month trapping schedule.

\subsection{Numerical Simulations}

We numerically solve the parameterized model to determine how different trapping regimes affect the persistence and long-term trends of the newt populations. Simulations are initialized at the crayfish-free equilibrium (648 adult newts and 550 total juveniles), and trapping begins when the number of crayfish is at carrying capacity (10,000 crayfish). We define newt extinction as having 5 or fewer adults. We do not define a crayfish extinction cutoff because crayfish resurgences have been observed from very small population sizes. Without human intervention under the given parameterization, the newt population goes extinct 24 years after the 6-year initialization period. Twenty-four years is the minimum possible time to newt extinction and is a by-product of the newt lifespan. In the figures that follow, time begins after the 6 -year initialization period. To evaluate 
Table 2. Optimal trapping months when trapping $T$ crayfish for a consecutive span of 2 or 5 years

\begin{tabular}{cccc}
\hline Num. Years & Trap T Crayfish & Optimal 3 Months & Optimal 6 Months \\
\hline \multirow{2}{*}{2} & $\leq 1,000$ & Nov, Mar, Apr & Aug-Nov, Mar-Apr \\
& $\geq 2,000$ & Nov, Mar, Apr & Mar-Aug \\
\hline & $\leq 600$ & Nov, Mar, Apr & Aug-Nov, Mar-Apr \\
5 & $800 \leq T \leq 2,000$ & Nov, Mar, Apr & Mar-Aug \\
& $\geq 3,000$ & Mar-May & Mar-Aug \\
\hline
\end{tabular}

Our model determines the optimal 3-month and 6-month trapping regimes by comparing the number of juveniles produced using every possible combination of 3 or 6 months, excluding the rainy winter months of December-February. Trapping up to $T$ crayfish per month begins immediately after initialization and ends after 2 consecutive years or 5 consecutive years. For later simulations we set the optimal 3 months as March-May and the optimal 6 months as March-August.

the effectiveness of the trapping regimes, we compare persistence or relative times to extinction of the adult newt population. These values will vary with the crayfish carrying capacity of a particular stream but give both a quantitative and qualitative sense of the effort needed for effective crayfish removal to promote newt persistence.

In Fig. 4, we vary the trapping capacity, $T$, between 0 and 5,000 crayfish per month and simulate trapping crayfish using the optimal monthly schedules at different yearly frequencies. We choose 5,000 crayfish per month as the upper limit because catches tend to be smaller in streams with comparable carrying capacities and the maximum catch recorded for one month in $400 \mathrm{~m}$ of Trancas Creek is 6,570 crayfish (Kats et al., 2013). We observe that if crayfish are present without trapping $(T=0)$, the newt population goes extinct 24 years after the 6 -year initialization period. When trapping is implemented every year, newts persist when $T \geq 2,000$ crayfish per month for 3 months or $T \geq 800$ crayfish per month for 6 months. If trapping occurs every other year, the newt population goes extinct for all $T$ values when trapping 3 months of the year and persists when $T \geq 2,000$ crayfish per month on the optimal 6-month trapping schedule.

Table 3 describes how the values of the crayfish trapping capacity, $T$, change the time to newt extinction from a baseline of 24 years under various trapping schedules. In general for each $T$, the 
Adult Newt
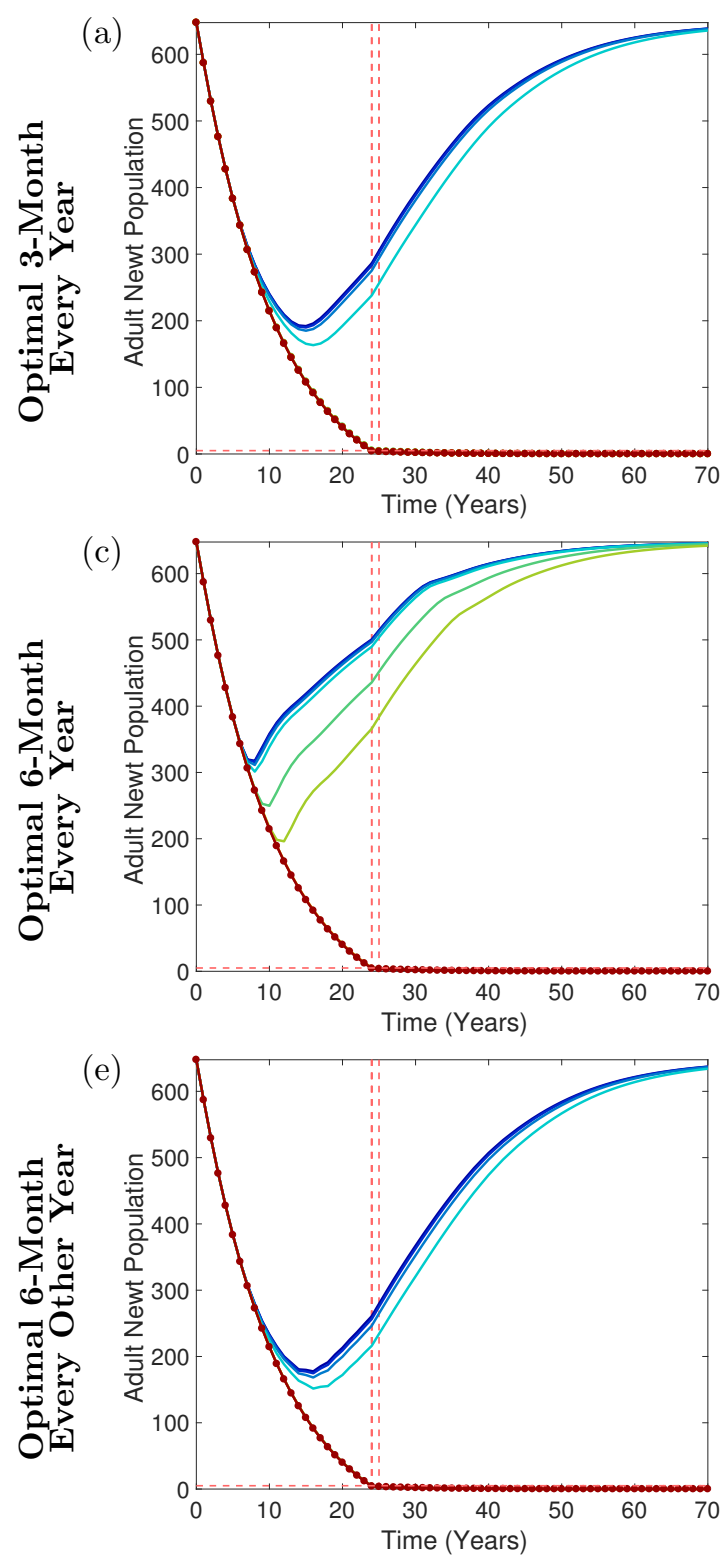

\section{Crayfish}

(b)

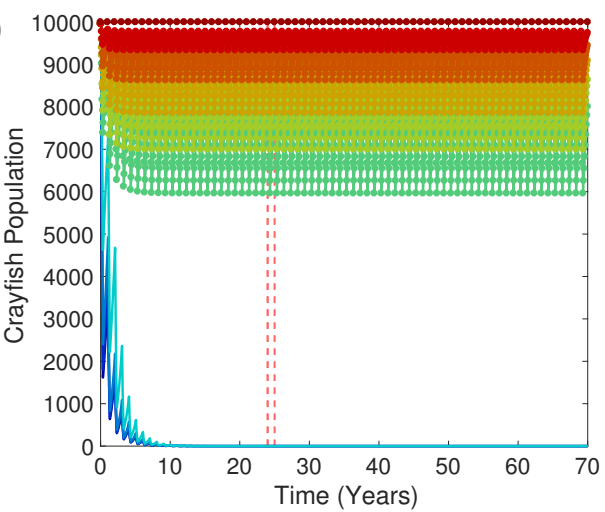

(d)

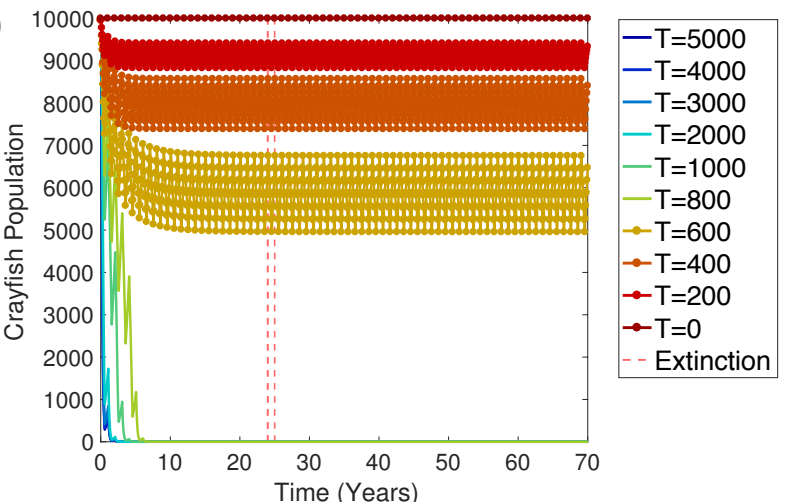

(f)

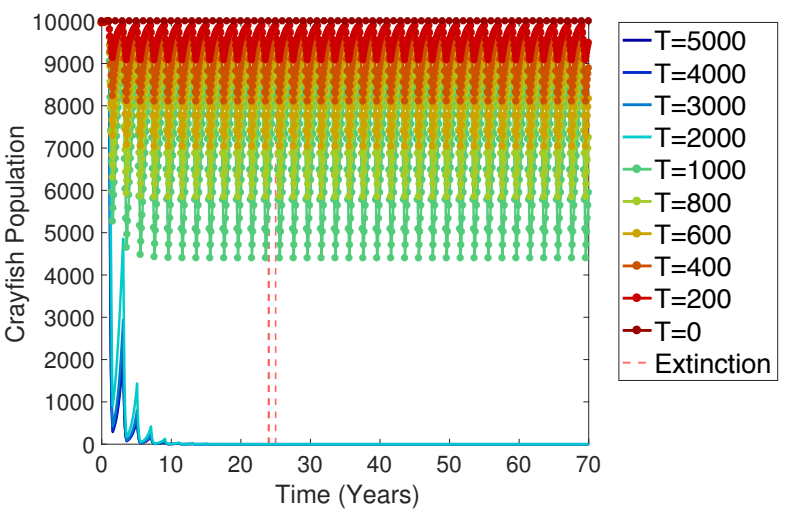

Fig. 4. Newt and crayfish population sizes when varying trapping schedules and trapping capacity,

T. Plots (a) and (c) show the adult newt populations, and (b) and (d) show the corresponding crayfish populations when trapping occurs every year under the $(\mathrm{a}, \mathrm{b})$ optimal 3-month and $(\mathrm{c}, \mathrm{d})$ optimal 6-month trapping schedules. Plot (e) is the adult newt population and (f) is the corresponding crayfish population when trapping occurs every other year using the optimal 6-month trapping regime. For lower values of $T$, newt populations go extinct earlier and are plotted as lines with dots. Smooth lines for higher $T$ values indicate that the newts persist. The case $T=0$ indicates that if no crayfish trapping is implemented, newt extinction occurs 24 years after the 6 -year initialization period. The horizontal red line denotes the extinction cutoff for adult newts, and the vertical red lines mark the time at which a newt population goes extinct. Newt populations that persist correspond to crayfish populations that go extinct, while newt populations that go extinct have substantial crayfish populations. 
optimal 6-month trapping regime is expectedly more effective than the optimal 3-month regime, which is in turn more effective than the traditional 3-month schedule. Long-term newt persistence occurs when trapping at least 2,000 crayfish every year. In the absence of persistence, time to extinction is extended by 1 year ( $4.2 \%$ increase) when intermediate trapping capacities are utilized annually with the optimal, but not traditional, trapping regimes. Trapping every other year exaggerates the comparative benefits of optimal and longer trapping schedules. In this case, time to extinction increases by more than 1 year for all trapping regimes with $T \geq 3,000$ crayfish per month and the optimal 3-month trapping schedule is nearly twice as effective as the traditional 3-month trapping regime.

To investigate how beneficial infrequent trapping can be, we restrict trapping to occur every $N$ th year and vary $N$ between 1 and 5 in Fig. 5 and Table 4 . We consider either low $(T=1,000$ crayfish per month) or high ( $T=5,000$ crayfish per month) trapping capacities and see that a high $T$ value can greatly extend time to extinction. Under the two optimal trapping regimes, newts persist when trapping occurs every year with $T=5,000$ crayfish per month. Otherwise, the optimal 6-month trapping schedule is at least three times more effective than either 3-month schedule, and only the optimal 6-month regime allows newts to persist when trapping every other year. Trapping every 5 th year using the optimal 6 -month regime extends the time to newt extinction by the same amount as trapping every other year under the optimal 3-month regime. Trapping a low amount ( $T=1,000$ crayfish per month) every year using the 6 -month regime prevents newt extinction and only the optimal trapping regimes prolong newt population survival. All other trapping frequencies fail to prevent newt extinction with the given trapping regimes and $T$ values.

In Table 5, we explore whether a one-time multiyear trapping program can reduce the crayfish population to negligible levels. That is, Table 5 examines model behavior when trapping for a span of 1,3 , or 4 consecutive years and then letting the ecosystem evolve without human intervention. The model predicts that trapping for a single year prolongs newt persistence only if implemented on a six-month schedule with enough resources to remove at least $T=3,000$ crayfish per month. Extra years of trapping provide meaningful improvements in newt population survival time. Trapping extends the time to extinction for all monthly regimes when trapping $T \geq 3,000$ crayfish per month for 3 years or $T \geq 2,000$ crayfish per month for 4 years. Increases in time to extinction are predicted to more than double when using the optimal 6-month versus 3-month trapping regime for multiple consecutive years. Using the optimal 3-month trapping regime instead of the traditional 3-month 
Table 3. Increase in time to extinction when trapping $T$ crayfish either every 1 or 2 years

\begin{tabular}{|c|c|c|c|c|}
\hline \multirow{3}{*}{$\begin{array}{c}\text { Trap Every } \\
\qquad N \text { th } \\
\text { Year }\end{array}$} & \multirow{3}{*}{ Trap $T$ Crayfish } & \multirow{2}{*}{\multicolumn{3}{|c|}{$\begin{array}{c}\text { Increase in Time to Extinction } \\
\text { Years (Percent Increase) }\end{array}$}} \\
\hline & & & & \\
\hline & & Trad. 3-Month & Optimal 3-Month & Optimal 6-month \\
\hline \multirow{4}{*}{1} & $\leq 400$ & $0(0 \%)$ & $0(0 \%)$ & $0(0 \%)$ \\
\hline & 600 & $0(0 \%)$ & $0(0 \%)$ & $1(4.2 \%)$ \\
\hline & $800,1,000$ & $0(0 \%)$ & $1(4.2 \%)$ & Persist \\
\hline & $\geq 2,000$ & Persist & Persist & Persist \\
\hline \multirow{5}{*}{2} & $\leq 800$ & $0(0 \%)$ & $0(0 \%)$ & $0(0 \%)$ \\
\hline & 1,000 & $0(0 \%)$ & $0(0 \%)$ & $1(4.2 \%)$ \\
\hline & 2,000 & $0(0 \%)$ & $1(4.2 \%)$ & Persist \\
\hline & 3,000 & $4(17 \%)$ & $8(33 \%)$ & Persist \\
\hline & $\geq 4,000$ & $5(21 \%)$ & $9(38 \%)$ & Persist \\
\hline
\end{tabular}

Time to extinction in the absence of trapping is 24 years, and the increased survival time beyond this is listed for several trapping regimes. Trapping occurs every $N$ th year. The smaller of $T$ or $\xi C$ crayfish is trapped each scheduled month. The traditional trapping schedule used in SMM streams is May-July, the optimal 3-month trapping schedule is March-May, and the optimal 6-month trapping schedule is March-August. 
Optimal 3-Month
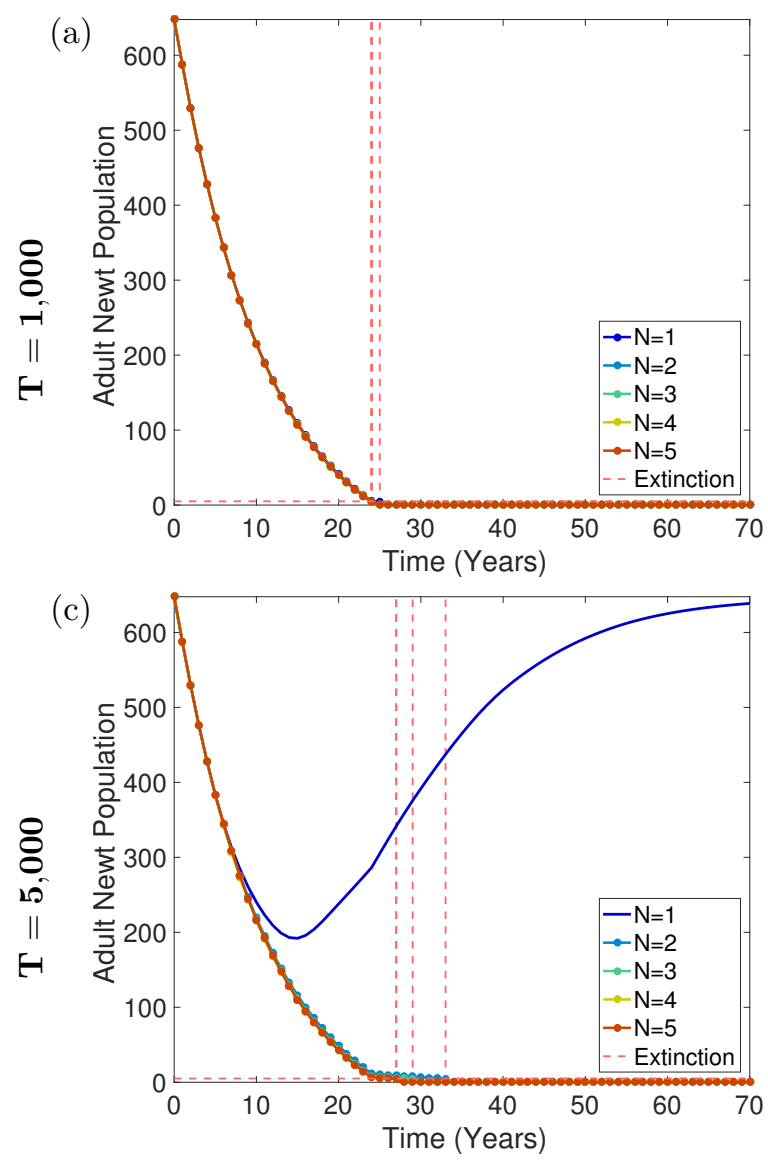

Optimal 6-Month

(b)

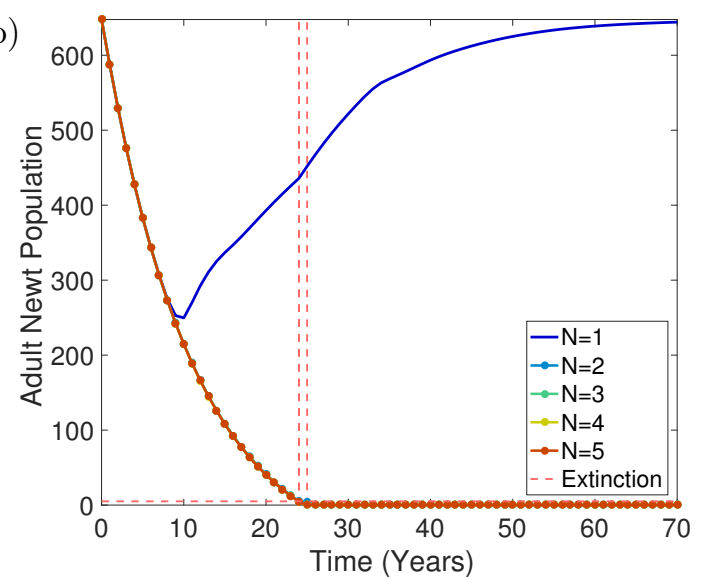

(d)

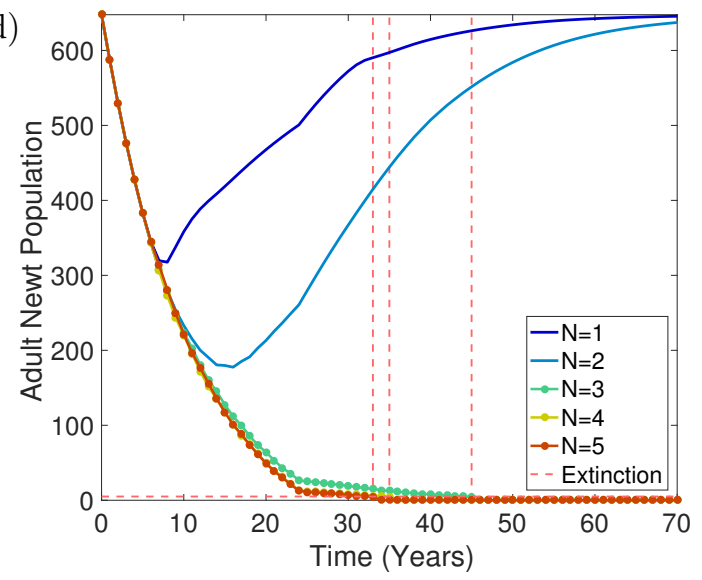

Fig. 5. Adult newt populations when trapping every $N$ th year with low and high values of $T$. In plots (a) and (b), a maximum of $T=1,000$ crayfish per month are trapped every $N$ years using (a) the optimal 3-month and (b) the optimal 6-month trapping schedule. In plots (c) and (d), $T=5,000$ crayfish per month are trapped every $N$ th year using (c) the optimal 3-month and (d) the optimal 6-month trapping schedule. For greater values of $N$, newt populations go extinct earlier and are plotted as lines with dots. Smooth lines for lower $N$ values mean that the newts persist. The horizontal red line denotes the extinction cutoff for adult newts, and the vertical red lines mark the time at which a newt population goes extinct. Persistence and later extinctions correspond with greater $T$ values and more frequent trapping (more months per year or smaller $N$ ). 
Table 4. Increase in time to extinction when trapping a low or high amount of crayfish per month every $N$ th year

\begin{tabular}{ccccc}
\hline \multirow{2}{*}{ Trap T Crayfish } & $\begin{array}{c}\text { Trap Every } \\
\text { Nth }\end{array}$ & \multicolumn{3}{c}{$\begin{array}{c}\text { Increase in Time to Extinction } \\
\text { Years }\end{array}$} \\
\cline { 2 - 5 } Year & Percent Increase) \\
\hline \multirow{2}{*}{1,000} & 1 & $0(0 \%)$ & $1(4.2 \%)$ & Persist \\
& 2 & $0(0 \%)$ & $0(0 \%)$ & $1(4.2 \%)$ \\
& 23 & $0(0 \%)$ & $0(0 \%)$ & $0(0 \%)$ \\
\hline 1 & Persist & Persist & Persist \\
& 2 & $5(21 \%)$ & $9(38 \%)$ & Persist \\
5,000 & 3 & $2(8.3 \%)$ & $5(21 \%)$ & $21(87 \%)$ \\
& 4 & $1(4.2 \%)$ & $3(13 \%)$ & $11(46 \%)$ \\
& 5 & $1(4.2 \%)$ & $3(13 \%)$ & $9(38 \%)$ \\
\hline
\end{tabular}

Time to extinction in the absence of trapping is 24 years, and the increased survival time is listed for several trapping regimes. Trapping occurs every $N$ th year. The smaller of $T$ or $\xi C$ crayfish is trapped each listed month. The traditional trapping schedule used in SMM streams is May-July, the optimal 3-month trapping schedule is March-May, and the optimal 6-month trapping schedule is March-August. 
schedule also prolongs time to newt extinction. These trends are naturally most pronounced with higher levels of trapping (high $T$ ).

Trapping for four consecutive years not only further prolongs newt extinction for all three trapping regimes, but it also allows some newt population recovery under the optimal 6-month trapping schedule. By comparing Fig. 6(a), where trapping is implemented at various $T$ values for 3 years and then stopped, versus Fig. 6(b), where trapping only occurs for 4 years, we see a temporary increase in the newt population with more months of trapping each year and $T \geq 2,000$ crayfish per month. This newt rebound is only temporary as a result of the continuous nature of the crayfish model (1), which never reaches absolute zero. However, the crayfish population size is driven below a single crayfish in these cases. Thus, our model predicts that crayfish extinction might be possible when trapping $T \geq 2,000$ crayfish per month for the optimal 6 months per year for 4 consecutive years. If crayfish extinction does occur, then the newt population rebounds to equilibrium levels.

\subsection{Sensitivity Analysis}

We examine model sensitivity to changes in $\beta_{C}$, the number of crayfish at which half of the female newts can lay eggs, and $\omega_{n}$, the number of crayfish-newt interactions per crayfish, by varying one parameter while the other is held constant. These parameters could not be determined by the available data and thus are determined by the methods described previously. The overall shape of the adult newt population plot is similar when varying $\beta_{C}$ or varying $\omega_{N}$ (not shown), but time to newt extinction changes, as described in Table 6 . Values of $\beta_{C}$ greater than the chosen 200 crayfish increase the time to newt extinction whereas smaller values maintain that the newt population goes extinct in 24 years. Likewise, $\omega_{N}=0.04$ interactions per crayfish is the threshold below which newts persist for up to 37 years and above which the newt population goes extinct in 24 years. Thus, we are using values of $\beta_{C}$ and $\omega_{N}$ that give conservative estimates for the time to newt extinction.

Model sensitivity to crayfish-specific parameters, such as the carrying capacity, population growth rate, and the two trapping terms, have been discussed previously when examining crayfish equilibria. In summary, larger crayfish growth rates, $r$, necessitate greater $\xi$ and $T$ values to achieve crayfish eradication. Changing the crayfish carrying capacity, $K_{C}$, only requires scaling $T$ to maintain similar dynamics. Jones et al. (2017) examines a similar newt model's sensitivity to $\beta_{N}$ and confirms the result in (14) that changes in the habitat space for egg-laying affects the 
Table 5. Increase in time to extinction when trapping $T$ crayfish for a one-time multiyear of years

\begin{tabular}{|c|c|c|c|c|}
\hline \multirow[t]{2}{*}{ Num. Years } & \multirow[t]{2}{*}{ Trap $T$ Crayfish } & \multicolumn{3}{|c|}{$\begin{array}{c}\text { Increase in Time to Extinction } \\
\text { Years (Percent Increase) }\end{array}$} \\
\hline & & Trad. 3-Month & Optimal 3-Month & Optimal 6-Month \\
\hline \multirow{3}{*}{1} & $\leq 2,000$ & $0(0 \%)$ & $0(0 \%)$ & $0(0 \%)$ \\
\hline & 3,000 & $0(0 \%)$ & $0(0 \%)$ & $1(4.2 \%)$ \\
\hline & $\geq 4,000$ & $0(0 \%)$ & $0(0 \%)$ & $2(8.3 \%)$ \\
\hline \multirow{4}{*}{3} & $\leq 800$ & $0(0 \%)$ & $0(0 \%)$ & $0(0 \%)$ \\
\hline & 1,000 & $0(0 \%)$ & $0(0 \%)$ & $1(4.2 \%)$ \\
\hline & 2,000 & $0(0 \%)$ & $1(4.2 \%)$ & $9(38 \%)$ \\
\hline & $\geq 3,000$ & $2(8.3 \%)$ & $4(17 \%)$ & $10(42 \%)$ \\
\hline \multirow{5}{*}{4} & $\leq 800$ & $0(0 \%)$ & $0(0 \%)$ & $0(0 \%)$ \\
\hline & 1,000 & $0(0 \%)$ & $0(0 \%)$ & $9(38 \%)$ \\
\hline & 2,000 & $2(8.3 \%)$ & $4(17 \%)$ & $12(50 \%)$ \\
\hline & 3,000 & $4(17 \%)$ & $6(25 \%)$ & $13(55 \%)$ \\
\hline & $\geq 4,000$ & $5(21 \%)$ & $7(29 \%)$ & $13(55 \%)$ \\
\hline
\end{tabular}

Time to extinction in the absence of trapping is 24 years, and the increased survival time is listed for several trapping regimes. The smaller of $T$ or $\xi C$ crayfish is trapped each scheduled month for a span of 1,3 , or 4 consecutive years. The traditional trapping timing used in SMM stream is May-July, the optimal 3-month trapping schedule is March-May, and the optimal 6-month trapping schedule is March-August. 


\section{3-Year Span}

(a)

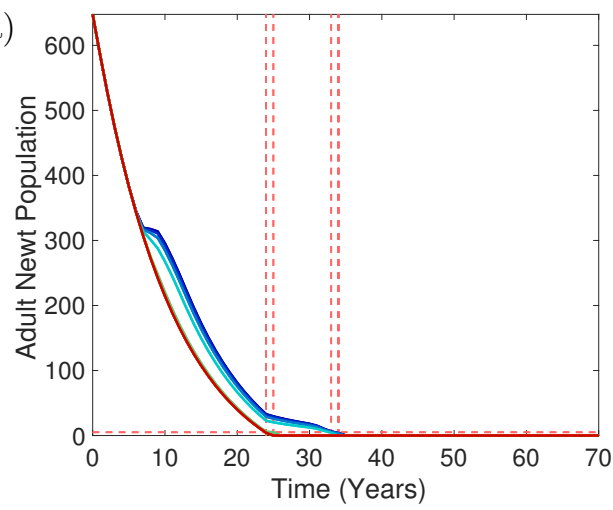

4-Year Span

(b)

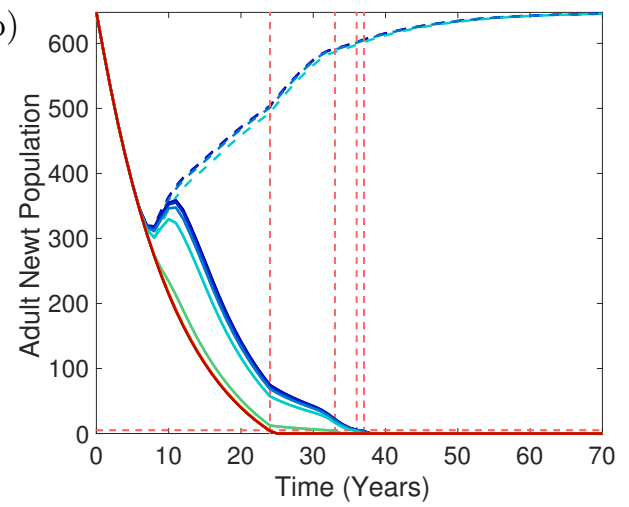

$-\mathrm{T}=5000$

$-\mathrm{T}=4000$

$-\mathrm{T}=3000$

$-\mathrm{T}=2000$

$-\mathrm{T}=1000$

$-\mathrm{T}=800$

$-\mathrm{T}=600$

- $\mathrm{T}=400$

$-\mathrm{T}=200$

- -Extinction

Fig. 6. Adult newt populations with a one-time multiyear trapping program of $T$ crayfish using the optimal 6 -month regime. Trapping begins immediately after initialization and ends (a) after 3 years and (b) after 4 years. In (b), newt populations temporarily increase after trapping $T \geq 2,000$ crayfish per month, but there is no temporary increase for any $T$ value in (a). Nevertheless, time to extinction is extended in both cases. The horizontal red line denotes the extinction cutoff for adult newts, and the vertical red lines mark the time at which a newt population goes extinct. Later extinctions correspond with higher trapping capacities, while temporary newt recovery occurs with longer trapping. In (b) but not (a), the number of crayfish drops below one crayfish when $T \geq 2,000$. If we implement a crayfish extinction cutoff at one crayfish, the respective newt populations rebound to equilibrium values, as shown with the dashed blue curves. Without the cutoff, the newt populations go extinct, as shown with the solid blue curves. 
magnitude but not the existence of the nontrivial newt equilibrium.

Table 6. Newt model sensitivity to $\beta_{C}$ and $\omega_{N}$ without trapping

\begin{tabular}{ccc}
\hline$\omega_{N}$ Interactions Per Crayfish & $\beta_{C}$ Crayfish & Time to Extinction \\
& $\leq 200$ & Years \\
\hline & 300 & 24 \\
0.04 & 400 & 26 \\
& 500 & 28 \\
& 1,000 & 29 \\
0 & 10,000 & 34 \\
0.01 & & 64 \\
0.02 & & 37 \\
0.03 & 200 & 33 \\
$\geq 0.04$ & & 30 \\
\hline
\end{tabular}

We vary $\beta_{C}$ between 0 and 10,000 crayfish and $\omega_{N}$ between 0 and 0.1334 , the maximum $\omega_{N}$ as described in (12). The parameter $\beta_{C}$ is the number of crayfish at which half of the female newts can lay eggs, and $\omega_{N}$ is the number of crayfish-newt interactions per crayfish. Total time to extinction is largest when $\omega_{N}$ is low or when $\beta_{C}$ is high. The values used in the model of $\beta_{C}=200$ crayfish and $\omega_{N}=0.04$ interactions per crayfish are thresholds at and below which newts go extinct at 24 years. This is the minimum possible time to extinction as dictated by the newt lifespan.

\section{Discussion}

We have constructed a mathematical model of California newt and invasive red swamp crayfish population dynamics. We use this model to investigate the effectiveness of crayfish trapping regimes to promote local newt persistence in the SMM streams. Under the given parameterization that uses values from the literature and field data whenever possible, the newt analytic persistence equation 
(17) predicts that newt and crayfish populations are unlikely to coexist long term. The model indicates that coexistence would require that the crayfish population be maintained at less than $0.5 \%$ of the carrying capacity. The unlikeliness of coexistence is further supported by our numerical simulations where in every tested scenario either the crayfish or newt population approaches zero. However, the model predicts that increased trapping efforts will decimate the crayfish population and promote newt persistence under some trapping regimes.

In order to prevent local newt extinction, crayfish trapping must occur with sufficient frequency and magnitude. To maximize the number of juvenile newts produced each year, our results indicate that crayfish trapping should begin in March and continue through the summer to protect newt egg-laying and subsequent aquatic life stages. Our model predicts that trapping more months of the year less frequently is equally if not more effective than trapping fewer months more frequently, even if the total number of months trapped is constant. Furthermore, there is a threshold effective trapping capacity for newt persistence that depends upon trapping frequency. For instance, lowcapacity trapping cannot prevent newt extinction even with frequent trapping.

Yet, the model predicts that some trapping scenarios that have insufficient resources or frequency to prevent newt extinction nevertheless will delay the time until newt extinction and thus may be justified. For instance, vigorously trapping crayfish for one year can extend the time until newt extinction by more than one year. Similarly, trapping that is not sustained can nevertheless have consequential effects. Under the model's parameterization, trapping for a single 3-year period can delay newt extinction by up to 10 years, whereas a 4-year period of trapping is predicted to cause a temporary newt population rebound that could in fact be permanent if the crayfish population is driven extinct. Prolonging time to extinction could allow for the implementation of alternative crayfish or newt management techniques, such as a captive newt breeding program. If annual precipitation increases, this also allows time for a possible flooding event to reduce the crayfish populations without human intervention.

Our model does not incorporate variable rainfall, which affects the number of newt eggs laid each year and the survival probability of newt larvae. Pools can shrink, and small pools can completely evaporate during drought conditions, which causes any aquatic life present to perish. Since Jones et al. (2017) predict that newt populations decline in severe drought, crayfish effects seen in our model would be further exacerbated by the inclusion of drought. Ignoring precipitation levels also means that crayfish are not naturally reduced via flooding, which could increase the effectiveness 
of trapping scenarios.

Despite extensive and prolonged observational data gathering on adult newts and newt eggs, our model is limited by a dearth of information about juvenile newts. Juveniles are notoriously difficult to study and are not tracked in field studies because they live in hidden terrestrial burrows and do not reliably return to streams until adulthood. Thus, we make the simplifying assumption that juvenile newts behave identically to adult newts except that they cannot breed. However, if juvenile newt annual survivorship was lower than adult newt survivorship, then trapping scenarios that only increase time to extinction would be less effective as even fewer newt offspring would reach adulthood. If, on the other hand, $100 \%$ of juveniles were to survive annually, times to extinction would increase by up to 10 years. However, the time until the newt population size drops below 20 newts would remain roughly the same (not shown). In either case, trapping regimes that lead to newt persistence are largely unaffected by changes in juvenile survivorship.

Our model simplifies crayfish population dynamics. Crayfish growth and reproduction is affected by temperature (Chucholl, C., 2011; Chen et al., 1995), yet our crayfish model (1) allows for equal population growth year-round. Additionally, our model does not incorporate crayfish breeding seasons or life stages. Allowing year-round growth and reproduction may overestimate the crayfish population and bias results toward crayfish persistence and newt extinction. A more thorough model of crayfish population dynamics can be found in Anastácio et al. (1999). Furthermore, crayfish often burrow into stream banks where they reside for up to weeks at a time, but this behavior is not explicitly described in our model (Correia and Óscar Ferreira, 1995). This is in part why we choose to not define a crayfish extinction threshold but rather allow crayfish to possibly rebound from near zero. Additionally, crayfish are being repeatedly introduced into many streams of interest, which is not accounted for in our model. For instance, in Trancas Creek the ponds at the head of the creek are infested with crayfish (Santa Monica Mirror, 2014). Thus, trapping keeps the crayfish population small enough to be negligible, but without sustained management the crayfish population may rebound.

Ultimately, this paper shows the potential of restorative measures to prevent local newt population extinction in the presence of invasive crayfish. Furthermore, we suggest the optimal months for crayfish trapping and predict that some trapping regimes can prevent or prolong the time until local newt extinctions. While extensive observational data gathering on adult newts and newt eggs informs our modeling, parameterization and corroboration of the model would be enhanced by 
more biological studies on the interactions between aquatic newts and crayfish in the wild. Modeling considerations discussed in this paper may therefore inform further field studies on crayfish management.

\section{Acknowledgements}

We thank undergraduate biology research students Alec Flores, William Ota, and Daniel Suh as well as Rodney Honeycutt, Thomas Vandergon, Stephen Davis, and Fred Adler for providing helpful insights and resources. We also thank Gary Bucciarelli for providing newt adult markrecapture data analysis estimates. This research was made possible by Jay Brewster and the Summer Undergraduate Research Program in Biology at Pepperdine University, which is funded by the National Science Foundation, Research Experience for Undergraduates, REU-Site Grant, DBI-1062721 and a National Science Foundation Supplement (DBI-1640759) to REU Site Grant DBI-1560352.

Anastácio, P. M., Nielsen, S. N., Marques, J. C., Nov. 1999. CRISP (crayfish and rice integrated system of production): 2. Modelling crayfish (Procambarus clarkii) population dynamics. Ecological Modelling 123 (1), 5-16.

Aquiloni, L., Brusconi, S., Cecchinelli, E., Tricarico, E., Mazza, G., Paglianti, A., Gherardi, F., May 2010. Biological control of invasive populations of crayfish: the European eel (Anguilla anguilla) as a predator of Procambarus clarkii. Biological Invasions 12 (11), 3817-3824.

Barbaresi, S., Gherardi, F., Sep. 2000. The invasion of the alien crayfish Procambarus clarkii in Europe, with particular reference to Italy. Biological Invasions 2 (3), 259-264.

Beddington, J. R., Feb. 1975. Mutual interference between parasites or predators and its effect on searching efficiency. Journal of Animal Ecology 44 (1), 331-340.

Brame, Jr., A. H., Dec. 1968. The number of egg masses and eggs laid by the California newt, Taricha torosa. Journal of Herpetology 2 (3/4), 169-170.

Bucciarelli, G. M., Honeycutt, R. L., Kats, L. B., unpublished.

Chen, S., Wu, J., Malone, R. F., 1995. Effects of temperature on mean molt interval, molting and mortality of red swamp crawfish (Procambarus clarkii). Aquaculture 131 (3), 205 - 217. 
Chucholl, C., 2011. Population ecology of an alien warm water crayfish (Procambarus clarkii) in a new cold habitat. Knowledge and Management of Aquatic Ecosystems. 401 (29).

Cook, B. I., Ault, T. R., Smerdon, J. E., Feb. 2015. Unprecedented 21st century drought risk in the American Southwest and central plains. Science Advances 1 (1), e1400082-e1400082.

Correia, A. M., Óscar Ferreira, Jan. 1995. Burrowing behavior of the introduced red swamp crayfish Procambarus clarkii (Decapoda: Cambaridea) in Portugal. Journal of Crustacean Biology 15 (2), $248-257$

Cox, G. W., Sep. 1999. Alien Species in North America and Hawaii. Island Press.

DeAngelis, D. L., Goldstein, R. A., O'Neill, R. V., Jul. 1975. A model for tropic interaction. Ecology $56(4), 881-892$.

Diffenbaugh, N. S., Swain, D. L., Touma, D., Mar. 2015. Anthropogenic warming has increased drought risk in California. Proceedings of the National Academy of Sciences 112 (13), 3931-3936.

Eversole, A. G., Mazlum, Y., 2002. Comparative fecundity of three Procambarus species. Journal of Shellfish Research 21 (1), 255-258.

Gamradt, S. C., Kats, L. B., Aug. 1996. Effect of introduced crayfish and mosquitofish on California newts. Conservation Biology 10 (4), 1155-1162.

Gamradt, S. C., Kats, L. B., May 1997. Impact of chaparral wildfire-induced sedimentation on oviposition of stream-breeding California newts (Taricha torosa). Oecologia 110 (4), 546-549.

Gamradt, S. C., Kats, L. B., Anzalone, C. B., Jun. 1997. Aggression by non-native crayfish deters breeding in California newts. Conservation Biology 11 (3), 793-796.

Geiger, W., Alcorlo, P., Baltans, A., Montes, C., 2005. Impact of an introduced Crustacean on the trophic webs of Mediterranean wetlands. In: Issues in Bioinvasion Science. Springer Netherlands, pp. 49-73, dOI: 10.1007/1-4020-3870-4_6.

Genovesi, P., 2005. Eradications of invasive alien species in Europe: a review. Biological Invasions 7 (1), 127-133. 
Gherardi, F., Acquistapace, P., Jul. 2007. Invasive crayfish in Europe: the impact of Procambarus clarkii on the littoral community of a Mediterranean lake. Freshwater Biology 52 (7), 1249-1259.

Gherardi, F., Holdich, D. M., Jun. 1999. Crayfish in Europe as Alien Species. CRC Press.

Gutirrez-Yurrita, P. J., Montes, C., Nov. 1999. Bioenergetics and phenology of reproduction of the introduced red swamp crayfish, Procambarus clarkii, in Doana National Park, Spain, and implications for species management. Freshwater Biology 42 (3), 561-574.

Hobbs, H. H., Jass, J. P., Huner, J. V., Jan. 1989. A review of global crayfish introductions with particular emphasis on two North American species (Decapoda, Cambaridae). Crustaceana 56 (3), $299-316$.

Houlahan, J. E., Findlay, C. S., Schmidt, B. R., Meyer, A. H., Kuzmin, S. L., Apr. 2000. Quantitative evidence for global amphibian population declines. Nature 404 (6779), 752-755.

Huner, J. V., 2009. Crawfish population dynamics as they affect production in several small, open commercial crawfish ponds in Louisiana. Proceedings of The Annual Meeting - World Mariculture Society 9 (1-4), 617-640.

Huner, J. V., Lindqvist, O. V., Feb. 1995. Physiological adaptations of freshwater crayfishes that permit successful aquacultural enterprises. American Zoologist 35 (1), 12-19.

Issa, F. A., Adamson, D. J., Edwards, D. H., Dec. 1999. Dominance hierarchy formation in juvenile crayfish Procambarus clarkii. Journal of Experimental Biology 202 (24), 3497-3506.

Jones, M. T., Milligan, W. R., Kats, L. B., Davis, C. L., Lucas, T. A., 2017. A discrete stagestructured model of newt population dynamics during a period of drought. Journal of Theoretical Biology 414, 245-253.

Kats, L., Pintor, L., Sih, A., Kerby, J., Jul. 2006. Aquatic Nuisance Species: A multi-stage approach to understanding the invasion ecology of exotic crayfish in Northern and Southern California. California Sea Grant College Program.

Kats, L. B., Bucciarelli, G., Vandergon, T. L., Honeycutt, R. L., Mattiasen, E., Sanders, A., Riley, S. P. D., Kerby, J. L., Fisher, R. N., Nov. 2013. Effects of natural flooding and manual trapping on 
the facilitation of invasive crayfish-native amphibian coexistence in a semi-arid perennial stream. Journal of Arid Environments 98, 109-112.

Kats, L. B., Ferrer, R. P., Mar. 2003. Alien predators and amphibian declines: review of two decades of science and the transition to conservation. Diversity and Distributions 9 (2), 99-110.

Marshall, C. J., Doyle, L. S., Kaplan, R. H., 1990. Intraspecific and sex-specific oophagy in a salamander and a frog: Reproductive convergence of Taricha torosa and Bombina orientalis. Herpetologica 46 (4), 395-399.

Martelloni, G., Bagnoli, F., Libelli, S. M., 2012. A dynamical population modeling of invasive species with reference to the crayfish Procambarus clarkii. Theoretical Biology Forum 105 (2), $47-69$.

McCallum, M. L., Sep. 2007. Amphibian decline or extinction? Current declines dwarf background extinction rate. Journal of Herpetology 41 (3), 483-491.

McClain, W. R., Mar. 1995. Growth of crawfish Procambarus clarkii as a function of density and food resources. Journal of the World Aquaculture Society 26 (1), 24-28.

Ramalho, R. O., Correia, A. M., Anastácio, P. M., Apr. 2008. Effects of density on growth and survival of juvenile red swamp crayfish, Procambarus clarkii (Girard), reared under laboratory conditions. Aquaculture Research 39 (6), 577-586.

Rhodes, R., Avault, Jr, J., 1986. Crayfish Procambarus clarkii production under two rice varieties, two levels of nitrogen fertilization, and two crayfish stocking rates. Freshwater Crayfish 6, 266269.

Riley, S. P. D., Busteed, G. T., Kats, L. B., Vandergon, T. L., Lee, L. F. S., Dagit, R. G., Kerby, J. L., Fisher, R. N., Sauvajot, R. M., Dec. 2005. Effects of urbanization on the distribution and abundance of amphibians and invasive species in Southern California streams. Conservation Biology 19 (6), 1894-1907.

Ritter, W. E., 1897. Diemyctylus torosus Esch.; the life-history and habits of the Pacific coast newt. The Academy, San Francisco. 
Santa Monica Mirror, June 2014. Major Malibu Golf Club redevelopment approved.

URL http://www.smmirror .com/articles/News/Major-Malibu-Golf-Club-Redevelopment-Approved/40509

Scalici, M., Gherardi, F., Mar. 2007. Structure and dynamics of an invasive population of the red swamp crayfish (Procambarus clarkii). Hydrobiologia 583 (1), 309-319.

Sever, D. M., Kramer, S. A., Duff, S., 1986. The relation between ovum variability and larval growth in Ambystoma tigrinum, Amphibia: Urodela. In: Proceedings of the Indiana Academy of Science. Vol. 96. Indiana Academy of Science, p. 594.

Sodhi, N. S., Bickford, D., Diesmos, A. C., Lee, T. M., Koh, L. P., Brook, B. W., Sekercioglu, C. H., Bradshaw, C. J. A., Feb. 2008. Measuring the meltdown: Drivers of global amphibian extinction and decline. PLOS ONE 3 (2), e1636.

Stuart, S. N., Chanson, J. S., Cox, N. A., Young, B. E., Rodrigues, A. S. L., Fischman, D. L., Waller, R. W., Dec. 2004. Status and trends of amphibian declines and extinctions worldwide. Science 306 (5702), 1783-1786.

Twitty, V. C., May 1937. Experiments on the phenomenon of paralysis produced by a toxin occurring in Triturus embryos. Journal of Experimental Zoology 76 (1), 67-104.

Twitty, V. C., 1942. The species of Californian Triturus. Copeia 1942 (2), 65-76.

Twitty, V. C., 1966. Of Scientists and Salamanders. W. H. Freeman and Company, Stanford University.

Underwood, E., 2015. Models predict longer, deeper U.S. droughts. Science 347 (6223), 707.

WRCC, August 2015. Western regional climate center. SOD monthly summary. URL http://www.wrcc.dri.edu/cgi-bin/climaIN.pl?ca5114 